\title{
Discriminated avoidance and escape conditioning with the tadpole (Rana pipiens)
}

\author{
WILLIAM J. HOYER and JAMES N. SHAFER \\ West Virginia University, Morgantown, W. Va. 26506 \\ and \\ JOHN E. MAULDIN and H. TODD CORBETT \\ Frostburg State College, Frostburg, Md. 21532
}

Five larval leopard frogs (Rana pipiens) were given 40 trials per day for 5 consecutive days in a discriminated avoidance situation. Light was used as the conditional stimulus (CS), and the unconditional stimulus (US) consisted of scrambled electric current. The response required was a forward movement to an adjoining segment of a circular water-filled alley. This response shaped up rapidly and was performed readily with repeated training. Compared to the appropriate control groups, there was a significant $(p<.01)$ increase in avoidance responding from $5.5 \%$ (Session 1) to $24.5 \%$ (Session 5 ). The results were discussed in terms of earlier difficulties in conditioning larval and adult frogs. The positive findings were attributed to the type of apparatus employed and the type of response required.

Investigations of avoidance and escape conditioning with larval and adult frogs have usually provided negative or inconclusive results. With the adult Rana pipiens (leopard frog), both Robinson (1967) and Boice (1970) failed to demonstrate either avoidance or escape learning, and McGill (1960) found an increase rather than a decrease in escape latencies with repeated training. In a classic study with Rana catesbeiana (bullfrog) tadpoles, Munn (1940) reported (in one of five Ss) some improvement in terms of first-unit responses in a four-blind multiple T-maze. In the same study, Munn was unable to reverse a phototropic response in $\mathrm{Hyla}$ versicolor (tree frog) tadpoles.

These results may be attributed either to the inability of this organism to learn a negatively reinforced response or to inappropriate and insensitive experimental procedures. With respect to the latter of these possibilities, recent reviews by Bolles (1970) and Seligman (1970) have emphasized the use of natural defensive responses when studying avoidance learning. For example, a species may be prepared to learn one type of avoidance response, termed by Bolles a species-specific reaction (SSDR), and may be less prepared or contraprepared to learn another type of response to avoid a particular stimulus. The purpose of the present experiment was to obtain discriminated avoidance and escape conditioning in the larval leopard frog, using a relatively natural response. \section{SUBJECTS}

Fifteen tadpoles, Rana pipiens, $3-4 \mathrm{~cm}$ long, were obtained locally. Sex and age were undetermined, but leg buds had not appeared on any of the Ss. The tadpoles were housed individually in plastic containers and were fed chopped dried flies daily. The water in the containers was an equal mixture of pond water and tap water, with the same proportion used in the test apparatus. Water temperature in the containers and in the test apparatus was maintained at $24^{\circ} \pm 1^{\circ} \mathrm{C}$. On arrival in the laboratory, the Ss were matched on the basis of size and assigned to one of three groups, five Ss in each group. The Ss were maintained in the laboratory for 8 days before testing. APPARATUS

A circular galvanized steel runway, $5 \mathrm{~cm}$ wide, $7.6 \mathrm{~cm}$ deep, and $206 \mathrm{~cm}$ in circumference, was employed. On a removable glass cover were 28 equally spaced radials which provided the 0 with a response criterion; a response was defined as the S's complete movement from one segment to an adjacent segment of the runway. The water mixture filled the alley to a height of approximately $6 \mathrm{~cm}$.

The conditional stimulus (CS) consisted of a change in illumination provided by four $75-\mathrm{W}$ light bulbs symmetrically spaced $30.5 \mathrm{~cm}$ above the apparatus. An 0.6-mA scrambled electric current applied to four equally spaced electrodes extending into the alley was the unconditional stimulus (US). Hunter timers and Foringer relay equipment were used in programming the CS and US contingencies, and a Standard Electric timer was used to record response latencies.

PROCEDURE

Experimental Ss received a standard discriminated avoidance procedure with a 10-sec CS-US interval and a mean intertrial interval (ITI) of $43 \mathrm{sec}$ (range $=28-71$ sec). Response latencies (from CS onset), avoidances (responses during the CS-US interval), escapes (responses during the US interval), and responses during the ITI were recorded. The US was terminated automatically if $S$ did not escape within $20 \mathrm{sec}$ of US onset, and the number of no-response trials was also recorded.

There were two control groups. A noncontingent (NC) control group received random presentations of a 10-sec CS and a 10-sec US, and responding did not terminate the $\mathrm{CS}$ or US. A contingent (C) control group received random presentations of a 10 -sec CS and a 20-sec US, with a response terminating the CS or US. For both groups all responses occurring during the CS, US, and ITI were recorded. The mean interval between CS and US presentations was $22 \mathrm{sec}$ (range $=15-39 \mathrm{sec}$ ) for the $\mathrm{C}$ and NC control Ss.

On Day 1, all Ss received 20 trials during which only the CS was presented. If $S$ responded to the $C S$ alone on 5 or more of the 20 trials or on more than 2 of the last 5 trials, it was eliminated from the experiment. Only one $\mathbf{S}$ was replaced for this reason.

The Ss in the experimental and $C$ control groups were given 20 shaping trials immediately following the 20 preconditioning trials with only the CS. During the first 5 shaping trials, the US was terminated if any movement occurred, and the response requirement was gradually increased during the next 5 trials. All $S$ s reached the criterion of five consecutive avoidance or escape responses by Trial 13. The NC control Ss were not shaped to respond.

Beginning on Day 2, the Ss were given 40 trials per day for 5 consecutive days (a total of 200 trials). All Ss were given $10 \mathrm{~min}$ of adaptation to the apparatus at the beginning of each daily session, and the number of adaptation responses was recorded.

RESULTS AND DISCUSSION

The mean percentage of avoidance responding for the experimental group was $17.7 \%$, as compared with $6.8 \%$ and $3.4 \%$ responses to the light by the $\mathrm{C}$ and NC control groups, respectively. These differences were significant $(F=17.65, \mathrm{df}=2 / 12, \mathrm{p}<.005)$. As can be seen in Fig. 1, there was an increase in avoidance responding with repeated training, and although the main effect of sessions was not significant $(\mathrm{F}=2.06, \mathrm{df}=4 / 48$, the Session by Group interaction was reliable $(F=3.33, \mathrm{df}=8 / 48, \mathrm{p}<.01)$.

It appeared that repeated trials suppressed responding for the NC control Ss, as evidenced by the number of ITI responses. The mean number of ITI responses per session for the NC control group was 48.2 , as compared with 221.0 for the 


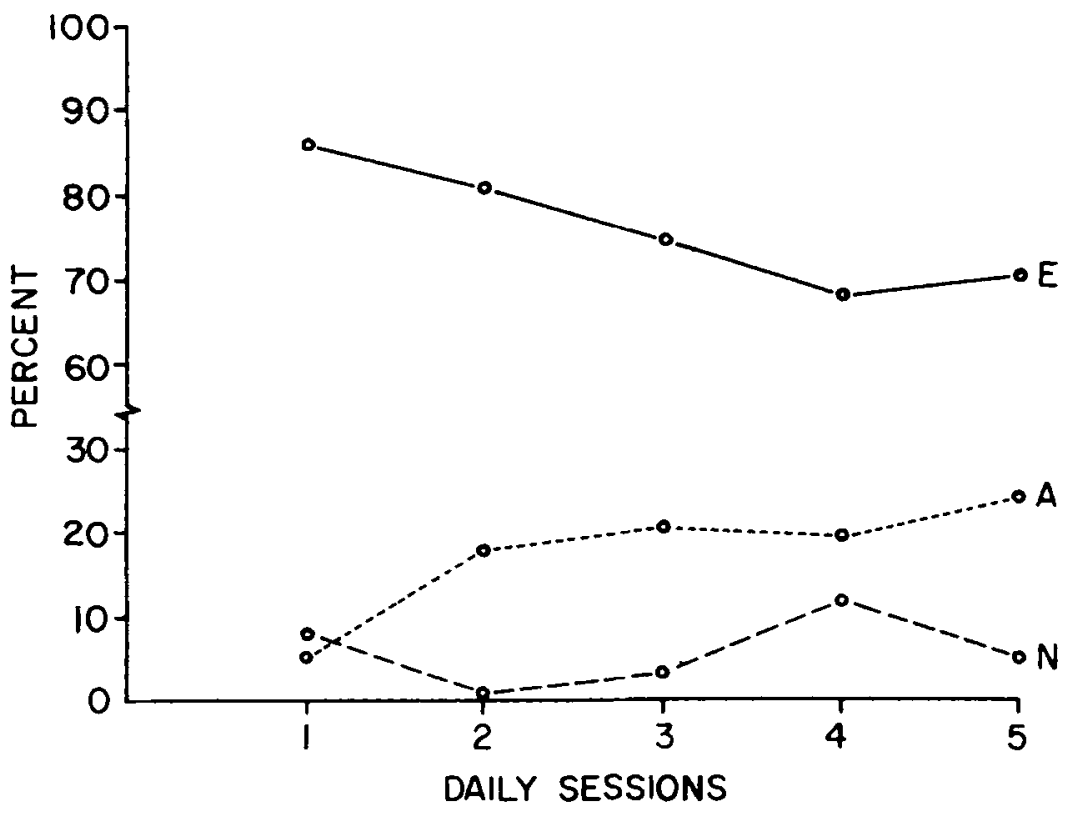

Fig. 1. Percent escapes (E), a voidances (A), and no-response trials (N) for the experimental Ss over 200 trials, divided into five blocks of 40 trials.

experimental group and 240.6 for the $C$ control group $(F=8.26, \mathrm{df}=2 / 12$, $p<.01)$. The response contingency did not affect the number of adaptation responses per session, however.

The experimental Ss avoided less in the first half of the session $(15.6 \%$ as compared with $19.8 \%$ ), suggesting a warm-up effect similar to that obtained with toads (Crawford \& Langdon, 1966) and lizards (Powell, 1967). However, there were more no-response trials in the second half of the session $(4.8 \%$ as compared with $7.2 \%)$. Over trials it appears that the number of avoidances increased at the expense of the number of escape responses. Although all within-sessions effects were nonsignificant, possibly shock effects were accumulating but were not attenuating the level of avoidance responding. The stability of the response latencies per session, in spite of the improvement in avoidance responding per session, supports this notion. These latencies were 18.32 , $18.29,19.53,18.81$, and $18.12 \mathrm{sec}$. The response latencies were not recorded in blocks of 20 trials in this study.

Response-contingent termination facilitated responsiveness to the US for the experimental and $\mathrm{C}$ control groups. The percentages of escape responding by the experimental Ss for the five sessions is shown in Fig. 1, and the mean percentage of escape responding was $76.3 \%$. The $\mathrm{C}$ control Ss escaped on $85.1 \%$ of the US presentations, and, over sessions, these percentages were $88.5,84.5,83.5$, 83.5 , and 85.5 , respectively. In comparison, the NC control Ss made only $21.4 \%$ responses to the US, and the percentages for the five sessions were $20.0,1^{\circ} 9.5,29.0,20.5$, and 18.0, respectively. The high degree of escape responding for the experimental and $\mathrm{C}$ control Ss is of importance, considering earlier difficulties in Rana pipiens using more complex and perhaps less natural topographies (Boice, 1970; McGill, 1960; Robinson, 1967).

On the basis of these results, it can be concluded that Rana pipiens larvae are capable of avoidance and escape learning. The success in conditioning both escape and avoidance might be attributed to the type of apparatus used and the topography of the required response. No direct comparisons wery made, but unpublished attempts by the authors to condition tadpoles using a commercially made shuttlebox were unsuccessful. In the shuttle apparatus, the organism would escape only if it obtaining this response with adult were facing the safe compartment. In the present study, however, the response necessary for CS and US termination was a forward movement of a relatively short distance and the organism was not required to reorient or to reenter a stimulus situation in which it had previously been shocked.

Using Bolles's (1970) terminology, it seems reasonable to consider this response requirement a SSDR to an aversive situation for both tadpoles and adults. Ontogenetic factors in avoidance and escape learning and the possibility of transfer of learning from the tadpole to the adult can be studied using such a response. Although it has been shown that frogs can learn an appetitive response under relatively natural conditions (Boice \& Witter, 1969; Van Bergeijk, 1967), similar results have not as yet been demonstrated in the tadpole. Furthermore, equating motivational factors may be less difficult using a negatively reinforced response, as has been suggested by Campbell (1967).

\section{REFERENCES}

BOICE, $R$. Avoidance learning in active and passive frogs and toads. Journal of Comparative \& Physiological Psychology, $1970,70,154-156$.

BOICE, R., \& WITTER, D. W, Hierarchical feeding behaviour in the leopard frog (Rana pipiens). Animal Behaviour, 1969, 17, 474-479.

BOLLES, R. C. Species-specific defense reactions and avoidance learning. Psychological Review, 1970, 77, 32-48.

CAMPBELL, B. A. Developmental studies of learning and motivation in infraprimate mammals. In $H$. $W$. Stevenson, E. H. Hess, and H. L. Rheingold (Eds.), Early behavior: Comparative and developmental approaches. New York: Wiley, 1967. Pp. 43-71.

CRAWFORD. F. T.. \& LANGDON, J. W. Escape and avoidance responding in the toad. Psychonomic Science, 1966, 6 , $115-116$.

MCGILL, T. E. Response of the leopard frog to electric shock in an escape-leaming situation. Joumal of Comparative \& Physiological Psychology, 1960, 53, 443-445.

MUNN, N. L. Learning experiments with larval frogs. Joumal of Comparative \& Physiological Psychology, 1940, 29, 97-108.

POWELL, R. W. Avoidance and escape conditioning in lizards. Psychological Reports, 1967, 20, 583-586.

ROBINSON, G. H. Discriminated avoidance and classical conditioning in the frog, $R$ ana pipiens. Unpublished doctoral dissertation. The University of Mississippi, 1967.

SELIGMAN, M.E. P. On the generality of the laws of learning. Psychological Review, 1970, 77, 406-418.

VAN BERGEIJK. W. A. Anticipatory feeding behaviour in the bullfrog (Rana catesbeiana). Animal Behaviour, 1967, 15, 231-238. 